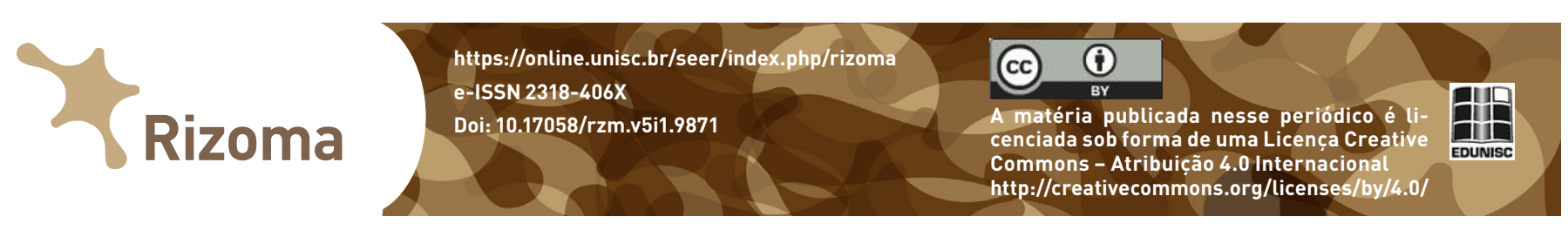

\title{
Entrevista
}

\section{Entrevista a Adriano Rodrigues}

Cada época com seus respectivos dispositivos técnicos e as formas de vigilância que lhes são correspondentes. Da Grécia Antiga ao mundo contemporâneo. Ao observar o papel dos dispositivos técnicos na sociedade atual, o professor e pesquisador da Universidade Nova de Lisboa, Adriano Rodrigues, aponta para um momento em que já não há mais distinção entre a condição de vigilante e de vigiado entre os indivíduos. São papeis, segundo ele, que sequer cumprimos agora por coerção, mas por prazer e cumplicidade. São as regras de uma nova esfera pública, marcada, entre outros, por formas de tirania em que, supostamente, nos defendemos da vigilância do outro, vigiando a nós mesmos.

1. Qual o papel dos dispositivos técnicos na relação estabelecida entre os monitoramentos resultantes das interações sociais e a vigilância também gerada nesse contexto? $\mathrm{E}$ o que se pode pensar em termos de porvir nessa perspectiva? Teremos mais qualidade em nossas relações tecno-sociais ou seremos mais vigiados?

Não creio que seja possível responder de maneira categórica às duas perguntas que coloca, a não ser que adotemos as posições fundamentalistas, quer dos que pressupõem que os dispositivos técnicos resolverão todos os problemas da humanidade, quer dos que pressupõem que os dispositivos técnicos são a causa de todos os males da humanidade. Ao longo dos anos e à medida que tenho vindo a refletir sobre o assunto, tenho procurado demarcar-me destas posições. Tanto os fundamentalismos tecnolatras como os fundamentalismos tecnofóbicos, para utilizarmos a terminologia de Gilbert Simondon, resultam de uma profunda ignorância antropológica, ignorância que contamina desastrosamente muitos estudos da comunicação.

No fundo, essas posições fundamentalistas decorrem da tendência que os seres humanos mostram para não aceitarem a sua condição. Repare que, se os seres humanos não inventassem dispositivos técnicos, não poderiam sobreviver neste planeta, pela simples razão de que os seus dispositivos naturais se encontram atrofiados e por isso incapazes de assegurar as funções vitais mais elementares. É por isso que a minha proposta consiste em adotar uma postura humilde de observação da maneira como as pessoas utilizam os dispositivos técnicos, se apropriam das suas potencialidades e vão contornando as suas eventuais perversões. Os estudiosos da comunicação não são uma espécie de gurus capazes de prever e de impor as melhores maneiras de as pessoas utilizarem os atuais dispositivos técnicos. É a comunidade dos

${ }^{1}$ É graduada em Comunicação Social Jornalismo pela Universidade Federal de Santa Maria (1992), licenciada em Letras-Inglês pela Universidade de Santa Cruz do Sul (2015) e doutora pelo Programa de Pós Graduação Em Comunicação da Pontifícia Universidade Católica do Rio Grande do Sul (2007). É professora adjunta da Universidade de Santa Cruz do Sul, onde atua como professora do Departamento de Comunicação Social e professora e pesquisadora do Programa de Mestrado e Doutorado em Letras da Unisc. Atualmente é Coordenadora de Pós Graduação Stricto Sensu da Universidade de Santa Cruz do Sul. Tem experiência na área de Comunicação, com ênfase em Teorias do Jornalismo, Jornalismo e Literatura, Narrativas Jornalísticas e Midiáticas, Jornalismo, Representações e Identidades, Telejornalismo e novas tecnologias. Integra os grupos de pesquisa Grupo de Estudos de Narrativas Literárias e Midiáticas (GENALIM - CNPQ) e o Grupo Interstitucional de Pesquisa em Telejornalismo (GIP - Tele). 


\section{Yizoma}

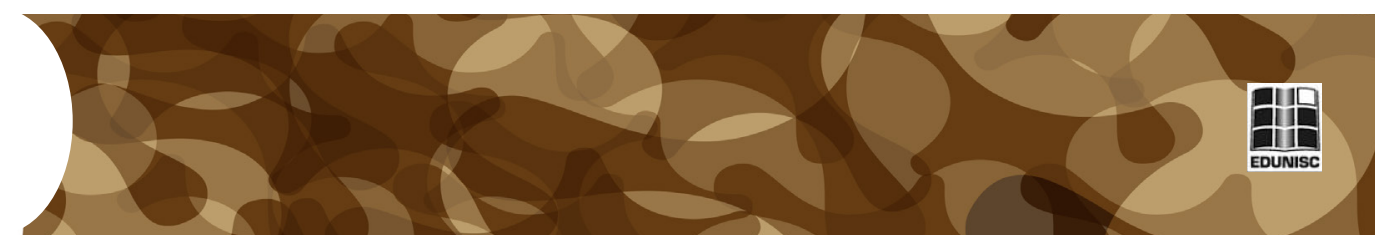

seres humanos que descobrirá o futuro que lhes pretende dar, independentemente dos nossos estudos e daquilo que cada um de nós pensa.

2. "A palavra escrita era um perigo para Platão da mesma forma que o Google e as câmeras de segurança são hoje para nós". O senhor estabelece uma relação entre as tecnologias comunicacionais e o corresponde tipo de vigilância que instituem socialmente, atentando para o fato de que contemporaneamente esta é mais eficaz por ser fruto da própria cooperação do vigiado. Comente.

É verdade que a vigilância é tanto mais eficaz quanto mais contar com a cooperação dos vigiados. Foi esta cooperação que, já no século XVIII, a invenção do dispositivo do panóptico procurou instituir. Em relação a este modelo, aquilo a que hoje parece estarmos assistindo já não é a institucionalização do dispositivo panóptico através da coerção, mas através do prazer e da cumplicidade das pessoas. Estas transformações parecem levar ao desaparecimento da diferença dos vigiados e dos vigilantes, uma vez que com os mais recentes dispositivos de vigilância somos todos, ao mesmo tempo, vigiados e vigilantes. Quando navegamos na internet, ao procurarmos caçar o rasto dos outros, o rasto dos nossos próprios comportamentos é ao mesmo tempo também caçado pelos outros. Os dispositivos de vigilância eletrônica funcionam, por isso, como uma espécie de fita de Moebius; anulam qualquer exterioridade ou escapatória. É com estas novas formas de vigilância que temos agora de saber lidar, procurando as soluções apropriadas.

3. Na sua perspectiva existe uma relação direta, ainda que ambígua e/ou dual com a vigilância fruto das possibilidades oferecidas pelas tecnologias comunicacionais, tanto no que pode assegurar em termos de condições de proteção e de segurança quanto de intrusão na vida do indivíduo. Como se caracteriza esta nova esfera pública descrita pelo senhor?

Toda a vigilância tem inevitavelmente os dois aspetos que refere. Não há vigilância sem intrusão. Este é o dilema com que todos nos confrontamos. Quem pretenda atentar contra a vida dos outros sabe que este dilema é uma armadilha em que somos todos inevitavelmente enredados. Os atuais dispositivos de vigilância tendem a converter todos em reféns, tanto as pessoas vigiadas como os vigilantes. $\mathrm{O}$ estado de sítio a que hoje estamos condenados é a arma mais perfeita e melhor lubrificada; é o novo rosto da tirania à qual ninguém escapa. Para nos prevenirmos da intrusão de eventuais perigos no nosso território nos vemos obrigados a introduzir no nosso território dispositivos de vigilância que coagem em permanência os nossos passos. Aquilo a que hoje damos o nome de terrorismo é, ao fim e ao cabo, o resultado do funcionamento destes dispositivos. Os governos estão bem conscientes do impasse a que a instituição do estado de sítio nos conduz. Vamos ter por isso que descobrir a maneira de o contornar.

4. Que relações se pode estabelecer entre os discursos resultantes das interações que se autorregulam em acordos tácitos nas redes sociais, como o senhor refere, e as manifestações fundamentalistas e/ 

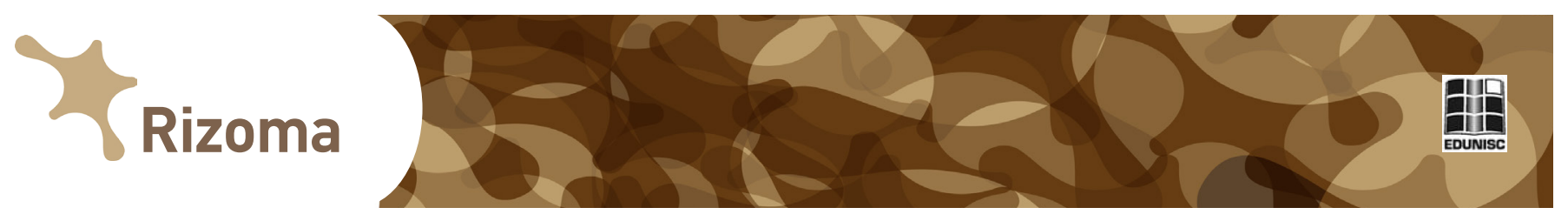

ou de ódio recorrentes nestes ambientes?

É impossível estabelecer uma relação direta entre a utilização das redes sociais e os fundamentalismos, até porque as redes sociais também são utilizadas para combater os fundamentalismos. O que podemos esperar é que os seres humanos consigam encontrar uma saída pra esta tensão, como o fizeram ao longo da história para os impasses decorrentes da invenção dos dispositivos técnicos que constituíram os ambientes interiorizados hoje na nossa experiência do mundo. Os dispositivos técnicos sempre foram usados, ao longo da história, como armas letais de que os seres humanos se serviram para alimentar fundamentalismos e ódio e, no entanto, acabaram também por servir para promover o entendimento, a arte e a harmonia entre os povos. O que podemos esperar é que consigam utilizar a sua razão e a sua sensibilidade para promoverem estes últimos objetivos.

5. O senhor defende a tese da improbabilidade da comunicação, ou seja, que é possível que os atores se entendam menos que mais. As novas interações decorrentes das condições ofertadas pelos gadgets tecnológicos ampliam esse risco da incomunicação? Por quê?

A improbabilidade da comunicação tem a ver com o fato de a interpretação que fazemos daquilo que os outros dizem e fazem, assim como daquilo que dizemos e fazemos decorrer de um processo de objetivação da experiência subjetiva de cada um, experiência que é, por definição, incomunicável. A improbabilidade da comunicação não tem propriamente a ver com os atuais dispositivos técnicos utilizados para comunicar. Tem a ver com o fato de sermos animais dotados de um corpo e de, por isso, só podermos comunicar através de manifestações corporais que escolhemos como adequadas àquilo que está em jogo em cada momento em que interagimos uns com os outros e com o mundo à nossa volta. Qualquer pessoa pode tomar consciência deste fato. Assim, por exemplo, os pais dão-se muitas vezes conta de que por mais que expliquem aos filhos aquilo que viveram quando tinham a idade deles, nunca conseguirão fazer com que eles vivam aquilo que eles viveram. É claro que os filhos ficam a saber aquilo que os pais lhes contaram. Mas, será que aquilo que eles pretendiam comunicar-lhes é aquilo que eles ficaram a saber? Duvido. Repare que aquilo que eles pretendiam comunicar nem eles próprios sabem bem o que era. É que a improbabilidade da comunicação não é apenas a da comunicação entre as pessoas, mas sobretudo a comunicação conosco próprios. Já está a ver que é uma tolice discutir da objetividade da comunicação, pressupondo que haverá uma comunicação autêntica em que as pessoas comunicam tudo aquilo que há para comunicar. Só seria possível uma comunicação autêntica se fossemos transparentes e se a vivência que temos ou se a nossa experiência subjetiva estivesse presente na comunicação. Dessa vivência nem nós próprios nos apercebemos quando a estamos vivendo. É só depois, quando alguma nova experiência a evoca, que nós selecionamos alguns fragmentos para os objetivarmos em expressões e comportamentos que os outros e nós próprios interpretamos. E este processo tanto ocorre nas conversas que temos entre nós, como nas mensagens que 


\section{$Y_{\text {Rizoma }}$}

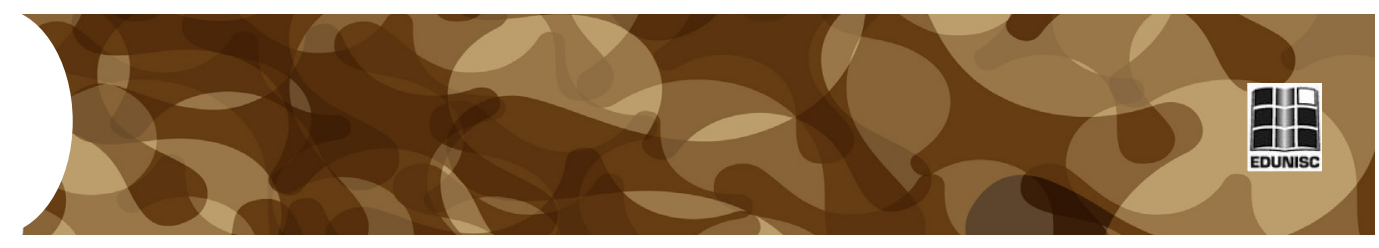

enviamos através das redes sociais ou nas reportagens jornalísticas. Costumo dizer que tudo e nada não existem. Aquilo que comunicamos é sempre fragmentário e imponderável. Ninguém está ao mesmo tempo no mesmo lugar das outras pessoas e, por isso, a sua experiência é sempre única. Ninguém pode repetir de novo a mesma experiência que teve e por isso a sua experiência é irrepetível.

6. A teoria dos sistemas a partir de Luhmann e a perspectiva da ecologia dos meios, via McLuhan oferecem um caminho, no seu entendimento, bastante vigoroso para a compreensão da sociabilidade contemporânea e suas complexidades. Como essas ideias podem ajudar a interpretar o sujeito em seu ambiente e seus comportamentos comunicacionais contemporâneos?

A perspectiva ecológica dos media não dá conta apenas da sociabilidade contemporânea, mas da sociabilidade de qualquer época e de qualquer sociedade. O sujeito é inevitavelmente o resultado aleatório de cada uma das interações entre os elementos ou as operações que constituem o sistema social. Talvez possamos dizer que o sujeito é um lugar único, singular e irrepetível. As pessoas não são sujeito; tornam-se uma multiplicidade de sujeitos em cada uma das interações em que se envolvem. Cada um de nós tem evidentemente uma identidade que o torna reconhecido, ao longo do tempo por todos quantos partilham de algum modo uma experiência comum, mas se torna um sujeito diferente para cada um, cada vez que interage com os outros.

Os dispositivos técnicos do nosso tempo, tal como os que foram inventados no passado, jogam evidentemente com esta natureza diferencial do sujeito, acelerando e aumentando a sua multiplicidade. Ao contrário do que dizem os que se autodesignam pós-modernos, não vejo as transformações do nosso tempo como uma rotura ou uma viragem, mas como a continuidade de um processo a que Gilbert Simondon dava o nome de sociogênese da técnica, processo que remonta à revolução do neolítico e que não parou desde então. Os novos dispositivos técnicos não fazem mais do que realizar as potencialidades que estavam já nas primeiras invenções técnicas da humanidade. A etapa atual tem como efeito o aumento da diferenciação do sujeito, decorrente da constituição de novos ambientes que dissolvem os ambientes constituídos pelas modalidades da escrita alfabética, ambientes que nos têm definido como sujeitos, ao longo dos últimos séculos. 